\title{
Evaluation of the World Health Organization 2009 classification of dengue severity in autopsied individuals, during the epidemics of 2011 and 2012 in Brazil
}

\author{
Luciano Pamplona de Góes Cavalcanti ${ }^{[1]}$, Deborah Nunes de Melo Braga ${ }^{[2]}$, \\ Margarida Maria de Lima Pompeu ${ }^{[2]}$, Antônio Afonso Bezerra Lima ${ }^{[3]}$, \\ Lívia Maria Alexandre da Silva ${ }^{[4]}$, Marina Gondim Aguiar ${ }^{[4]}$, \\ Mariana Castiglioni[ ${ }^{[4]}$, Fernanda Montenegro de Carvalho Araújo ${ }^{[5]}$, \\ Daniele Lima Malta ${ }^{[6]}$ and Anastácio Queiroz ${ }^{[2],[3]}$
}

[1]. Departamento de Saúde Comunitária, Universidade Federal do Ceará, Fortaleza, Ceará, Brasil. [2]. Departamento de Patologia, Universidade Federal do Ceará, Fortaleza, Ceará, Brasil. [3]. Hospital São Jose de Doenças Infecciosas, Fortaleza, Ceará, Brasil. [4]. Faculdade de Medicina, Centro Universitário Christus, Fortaleza, Ceará, Brasil. [5]. Laboratório Central de Saúde Pública do Ceará, Fortaleza, Ceará, Brasil. [6]. Universidade de Fortaleza, Fortaleza, Ceará, Brasil.

\begin{abstract}
Introduction: The dengue classification proposed by the World Health Organization (WHO) in 2009 is considered more sensitive than the classification proposed by the WHO in 1997. However, no study has assessed the ability of the WHO 2009 classification to identify dengue deaths among autopsied individuals suspected of having dengue. In the present study, we evaluated the ability of the WHO 2009 classification to identify dengue deaths among autopsied individuals suspected of having dengue in Northeast Brazil, where the disease is endemic. Methods: This retrospective study included 121 autopsied individuals suspected of having dengue in Northeast Brazil during the epidemics of 2011 and 2012. All the autopsied individuals included in this study were confirmed to have dengue based on the findings of laboratory examinations. Results: The median age of the autopsied individuals was 34 years (range, 1 month to 93 years), and 54.5\% of the individuals were males. According to the WHO 1997 classification, 9.1\% (11/121) of the cases were classified as dengue hemorrhagic fever (DHF) and 3.3\% (4/121) as dengue shock syndrome. The remaining $87.6 \%(106 / 121)$ of the cases were classified as dengue with complications. According to the 2009 classification, $100 \%(121 / 121)$ of the cases were classified as severe dengue. The absence of plasma leakage (58.5\%) and platelet counts $<100,000 / \mathrm{mm}^{3}(47.2 \%)$ were the most frequent reasons for the inability to classify cases as DHF. Conclusions: The WHO 2009 classification is more sensitive than the WHO 1997 classification for identifying dengue deaths among autopsied individuals suspected of having dengue.
\end{abstract}

Keywords: Dengue fever. Classification criteria. Warning signs. Vigilance and Control.

\section{INTRODUCTION}

Dengue is a major public health problem worldwide ${ }^{(1)(2)}$. The dengue cases in Brazil account for approximately $60 \%$ of all the dengue cases reported to the World Health Organization (WHO) from the Americas ${ }^{(3)}$. In the State of Ceará in Northeast Brazil, dengue was first noted in 1986, and it has since been endemic to the region, with many documented epidemics ${ }^{(4)(5)}$.

There are difficulties in the classification of dengue cases using the WHO 1997 classification; therefore, since 2001, Brazil

Corresponding author: Dr. Luciano Pamplona de Góes Cavalcanti. Depto. de Saúde Comunitária/UFC. Rua Prof. Costa Mendes 1608/5² andar, 60430-140 Fortaleza, Ceará, Brasil.

Phone: 5585 99987-8969

e-mail: pamplona.luciano@gmail.com

Received 21 August 2015

Accepted 11 November 2015 has adopted the term dengue with complications (DWC) ${ }^{(4)(6)}$. However, the term DWC has been used only in Brazil, and its use has complicated comparisons of dengue rates between Brazil and other countries ${ }^{(7)(8)}$.

In this context, based on a multicenter study [Dengue Control (DENCO)], the WHO proposed a new classification system in 2009 (WHO 2009 classification) ${ }^{(9)}$. This classification includes cases of dengue without warning signs, dengue with warning signs, and severe dengue $(\mathrm{SD})^{(9)(10)}$.

Many studies across the world have shown a higher sensitivity and greater ability to include a large number of cases with the WHO 2009 classification that with the WHO

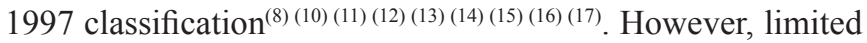
evidence exists on the impact of the WHO 2009 classification on the notification of deaths and on the evaluation of dengue fatality indicators around the world ${ }^{(18)}$.

In Northeast Brazil, where dengue is endemic, autopsies have identified many deaths caused by dengue, although dengue was not suspected during the clinical courses of 
the patients ${ }^{(19)}$. No previous study has assessed the ability of the WHO 2009 classification to identify dengue deaths among autopsied individuals suspected of having dengue. The objective of the present study was to evaluate the ability of the WHO 2009 classification to identify dengue deaths among autopsied individuals suspected of having dengue in Northeast Brazil.

\section{METHODS}

\section{Study design}

This retrospective study evaluated dengue deaths among autopsied individuals suspected of having dengue at the Coroner's Office Dr. Rocha Furtado (CO-RF), Northeast Brazil, during the epidemics of 2011 and 2012.

All the individuals suspected of dengue were reported to the Center for Epidemiological Surveillance of the State Department of Health for epidemiological investigation. Following the report of a suspected case, the epidemiological surveillance team of the state investigates the case to confirm or exclude dengue $^{(4)(6)(18)(20)}$.

Data were collected from January 2011 to December 2012 using a structured questionnaire. The data included age, sex, symptoms and signs, warning signs, shock evidence (signs of poor perfusion and hypotension), effusion (ascites, pleural effusion, pericardial effusion, and respiratory distress), laboratory test results, and autopsy findings.

We systematically retrieved data from medical records, notification forms used by the Brazilian Ministry of Health, and laboratory test records for all reported cases of dengueassociated deaths during the study period.

\section{Ethical considerations}

This study followed the ethical principles of research involving human subjects prepared by the National Health Council of Brazil and was approved by the Ethics Review Boards of Centro Universitário Christus - UNICHRISTUS (protocol \#011/2011) and Hospital São José de Doenças Infecciosas (protocol \#078/2011). Identifying information in the medical records was codified to preserve confidentiality.

\section{Patients and definitions}

In this study, the autopsied individuals suspected of having dengue had features clinically consistent with dengue, and they underwent reverse transcription polymerase chain reaction, NS1 antigen enzyme-linked immunosorbent assay, immunoglobulin $\mathrm{M}$ antibody assay, virus isolation, or immunohistochemistry to confirm the presence of dengue. All the autopsied individuals included in this study were confirmed to have dengue based on the findings of the laboratory examinations.

Patients were considered to have dengue fever (DF), dengue hemorrhagic fever (DHF), or dengue shock syndrome (DSS) according to the WHO 1997 classification $^{(21)}$. Dengue with complications cases included those that did not fulfill the DHF/

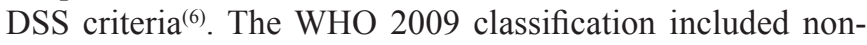
severe dengue (NSD) and $\mathrm{SD}^{(9)}$.
In this study, leukopenia was defined as a leukocyte count $<1,000 / \mathrm{mm}^{3}$, hypoalbuminemia was defined as a serum albumin level $<3 \mathrm{~g} / \mathrm{dL}$, liver injury was defined as an aspartate aminotransferase or alanine aminotransferase level $<1,000 \mathrm{U} / \mathrm{L}$, and severe thrombocytopenia was defined as a platelet count $<20,000 / \mathrm{mm}^{3}$.

\section{Statistical analysis}

Data were stored in Microsoft Office Access version 2010 (Microsoft Corp., Redmond, WA) and analyzed using Epi Info version 3.5.1 (Centers for Disease Control, Atlanta, GA). Data were classified in accordance with the classification systems used currently in Brazil adapted from the WHO 1997 classification and the WHO 2009 classification. The descriptive analyses included the frequencies of quantitative variables, number of deaths, and case-fatality rates.

\section{RESULTS}

A total of 121 dengue deaths were investigated, and of these, $66(54.5 \%)$ were assessed in 2011 and 55 (45.5\%) were assessed in 2012. Virus isolation was possible in 20 individuals, and of these individuals, $15(75 \%)$ had dengue virus serotype 1 (DENV-1), 3 (15\%) had dengue virus serotype 4 (DENV-4), and $2(10 \%)$ had dengue virus serotype 3 (DENV-3). The median age at death was 34 years (range, 1 month to 93 years), and $54.5 \%$ of the individuals were males.

According to the WHO 1997 classification, 9.1\% (11/121) of the cases were classified as DHF and 3.3\% (4/121) as DSS. The remaining $87.6 \%(106 / 121)$ of the cases were classified as DWC. According to the 2009 classification, 100\% (121/121) of the cases were classified as SD (Table 1).

The absence of plasma leakage (58.5\%) and platelet counts $<100,000 / \mathrm{mm}^{3}(47.2 \%)$ were the most frequent reasons for the inability to classify cases as DHF (Table 2).

Of the 106 cases classified as DWC, 9 (8.5\%) did not fulfill any of the four criteria for DHF according to the WHO 1997 classification, 38 (35.8\%) did not fulfill three criteria, 28 (26.4\%) did not fulfill two criteria, and 31 (29.3\%) did not fulfill one criteria.

According to the WHO 2009 classification, of the 106 cases classified as DWC, 21 (19.8\%) had severe plasma leakage, $24(22.6 \%)$ had severe bleeding, and $61(57.6 \%)$ had severe organ involvement. Among the 21 cases with severe plasma leakage, $15(71.4 \%)$ developed shock and $6(28.6 \%)$ had pleural effusion with respiratory distress. Among the 61 cases with severe organ involvement, $34(55.7 \%)$ had lesions in the central nervous system, $12(19.7 \%)$ had lesions in the lungs, $10(16.4 \%)$ had lesions in the heart, and $5(8.2 \%)$ had lesions in the liver (Figure 1).

With respect to the signs and symptoms, fever was noted in $87 \%(100 / 115)$ of the cases, and respiratory distress syndrome, persistent vomiting, cough, prostration, dyspnea, and abdominal pain were noted in over $70 \%$ of the cases (Table 3).

Table 4 shows that the mean platelet count was $71,000 / \mathrm{mm}^{3}$ (range, 0 to $487,000 / \mathrm{mm}^{3}$ ). 
TABLE 1 - Comparison of the World Health Organization 1997 classification adapted by Brazil and the WHO 2009 classification for the 121 autopsied individuals in Northeast Brazil in the 2011 and 2012 dengue epidemics.

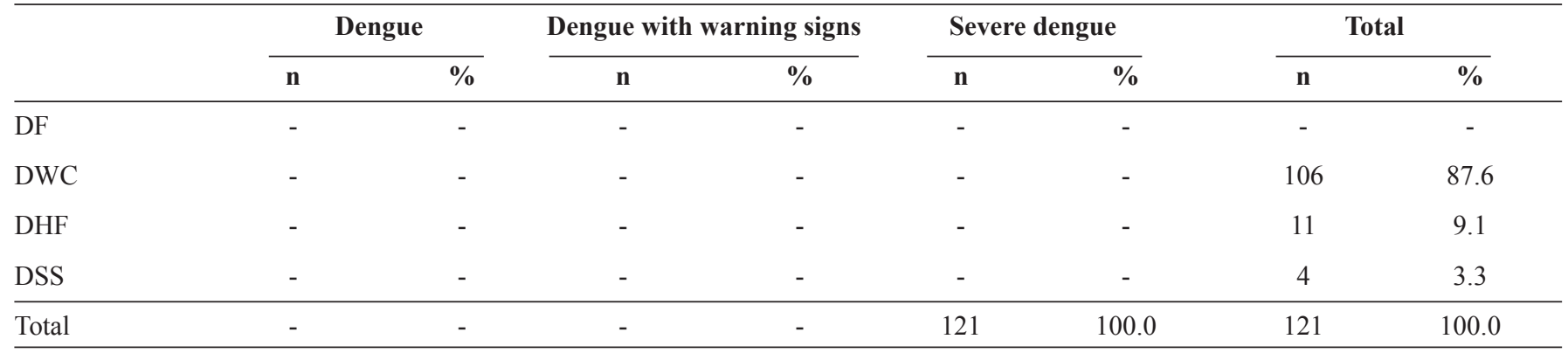

WHO: World Health Organization; DF: dengue fever; DWC: dengue with complications; DHF: dengue hemorrhagic fever; DSS: dengue shock syndrome.

TABLE 2 - Criteria not met in the 106 cases for classification as DHF.

\begin{tabular}{|c|c|c|}
\hline Criterion & Number & Percentage \\
\hline Plasma leakage & 62 & 58.5 \\
\hline Platelet count $<100,000 / \mathrm{mm}^{3}$ & 25 & 47.2 \\
\hline Bleeding & 16 & 26.2 \\
\hline Fever & 15 & 15.0 \\
\hline
\end{tabular}

DHF: dengue hemorrhagic fever.

TABLE 3 - Signs and symptoms of the 121 cases of dengue-related death during the 2011 and 2012 epidemics in the State of Ceará, Brazil.

\begin{tabular}{|c|c|c|}
\hline Signs and symptoms & Number/total & Percentage \\
\hline Fever & $100 / 115$ & 87.0 \\
\hline Respiratory discomfort & $79 / 92$ & 85.9 \\
\hline Persistent vomiting & $76 / 95$ & 80.0 \\
\hline Cough & $67 / 88$ & 76.1 \\
\hline Prostration & $41 / 56$ & 71.9 \\
\hline Myalgia & $49 / 73$ & 67.1 \\
\hline Somnolence & $45 / 70$ & 64.3 \\
\hline Arthralgia & $24 / 54$ & 44.4 \\
\hline Hematemesis & $25 / 65$ & 38.5 \\
\hline Petechiae & $24 / 64$ & 37.5 \\
\hline Convulsion & $22 / 63$ & 34.9 \\
\hline Retro-orbital pain & $14 / 51$ & 27.5 \\
\hline Melena & $13 / 57$ & 22.8 \\
\hline Bruise & $12 / 56$ & 21.4 \\
\hline
\end{tabular}




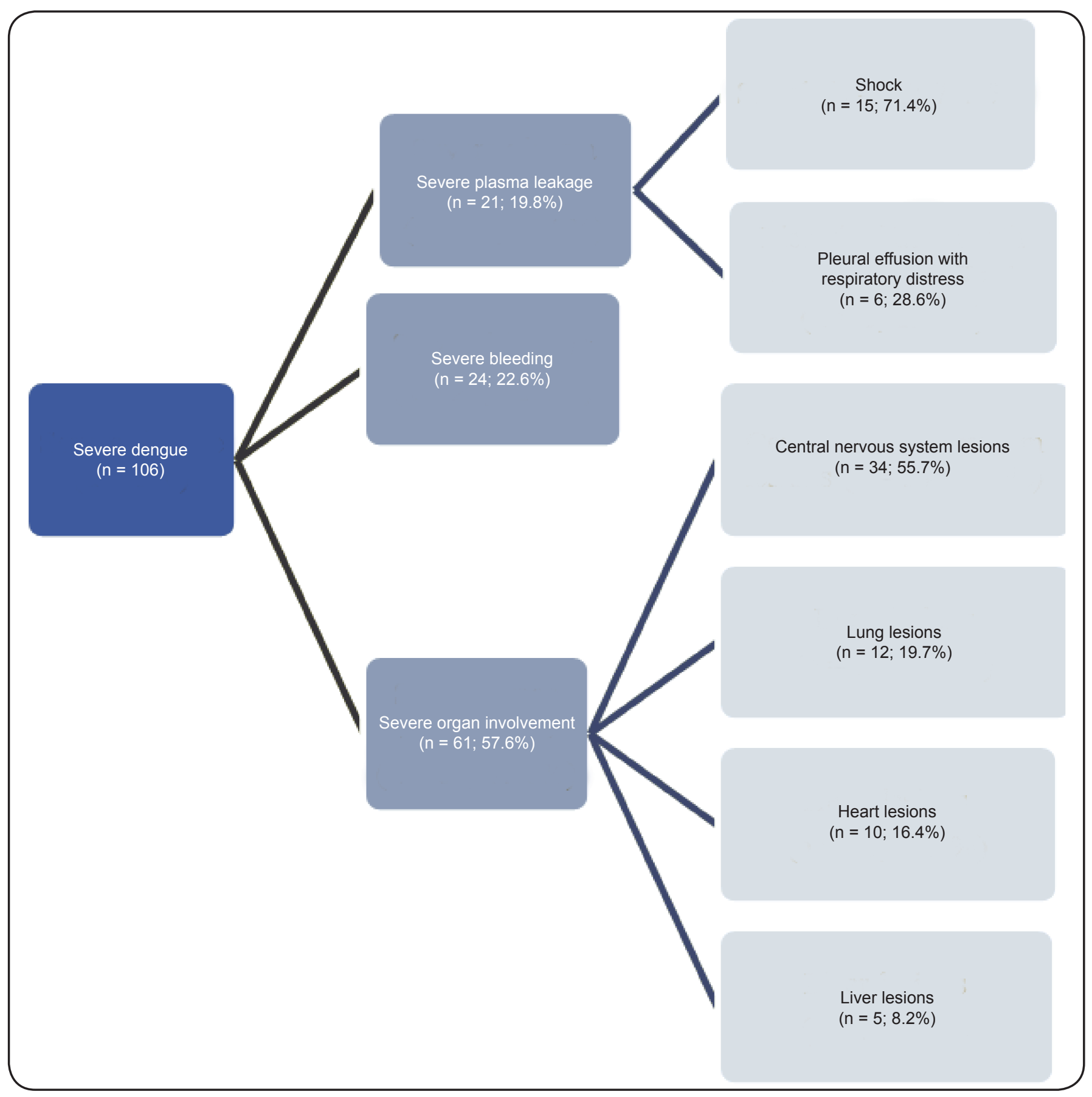

FIGURE 1 - Characteristics of the 106 cases classified as dengue with complications according to the World Health Organization 1997 classification adapted by Brazil and as severe dengue according the 2009 WHO classification. WHO: World Health Organization.

TABLE 4 - Laboratory results of the 121 cases of dengue-related death during the 2011 and 2012 epidemics in the State of Ceará, Brazil.

\begin{tabular}{|c|c|c|c|c|c|}
\hline Laboratory parameters & Minimum & Mean & Median & $75^{\text {th }}$ percentile & Maximum \\
\hline Platelet count $\left(/ \mathrm{mm}^{3}\right)$ & 0 & 104,950 & 71,000 & 148,500 & 487,000 \\
\hline Lower hematocrit (\%) & 9.3 & 29.7 & 29.2 & 38.7 & 51.6 \\
\hline White blood cell $\left(/ \mathrm{mm}^{3}\right)$ & 1,000 & 13,936 & 9,800 & 19,400 & 64,500 \\
\hline $\operatorname{AST}(\mathrm{U} / \mathrm{L})$ & 29 & 460 & 129 & 302 & 3,200 \\
\hline
\end{tabular}

AST: aspartate aminotransferase; ALT: alanine aminotransferase; U/L: units per liter. 
Of the 121 dengue-associated deaths, 27 (22.3\%) occurred in the absence of medical assistance and 94 (77.7\%) occurred after hospitalization.

\section{DIscussion}

In the present study, of the 121 cases, $106(87.6 \%)$ were not classified as DHF/DSS because the WHO 1997 criteria were not fulfilled, which indicates the low sensitivity of the WHO 1997 classification for the detection of severe cases ${ }^{(8)}(15)(16)(17)(22)$ and emphasizes the importance of adopting the WHO 2009 classification $^{(10)}$. Using the WHO 2009 classification, we found that all autopsied individuals in this study could be considered as having SD, suggesting that the WHO 1997 classification is unable to identify severe cases, including those with a high probability of death. Based on these findings, from an epidemiological viewpoint, countries that use only the DHF criteria in a strict sense may tend to underreport dengue-associated deaths when considering only deaths due to $\mathrm{DHF}^{(23)}$.

In the present study, five laboratory techniques were used to evaluate the presence of the dengue virus. The Brazilian Ministry of Health and the State Department of Health in Ceará recommend that all dead individuals suspected of having dengue undergo post-mortem examination ${ }^{(6)}$, and this protocol allows the confirmation of dengue in suspected dengue deaths that would have been otherwise unconfirmed ${ }^{(19)}$. Findings from previous studies reinforce the importance of using techniques to confirm dengue in post-mortem examinations of individuals suspected of having dengue, especially children ${ }^{(15)(24)}$.

The post-mortem examinations performed by the Coroner's Office Dr. Rocha Furtado identified the presence of plasma leakage and bleeding, and evidence of comorbidities that were not reported during the clinical course of the disease. These findings contributed to the classification of the cases as DHF, although the cases did not completely fulfill the WHO 1997 criteria, and similar findings have been reported in other countries ${ }^{(2)(2)}$. A recent study of 13 autopsied children with dengue reported thrombocytopenia in all the children ${ }^{(23)}$. However, in that study, only individuals who fulfilled all four criteria for DHF according to the WHO 1997 classification underwent post-mortem examination. Comparison of this previous study with the present study is difficult because in the previous study, autopsies were performed because a diagnosis of DHF had already been made, while in the present study, dengue was diagnosed only after the post-mortem examination.

Many studies have reported on autopsies of patients who died from dengue; however, most of the patients in those studies died from DHF. In the present study, the majority of dengue cases did not fulfill all the criteria for DHF/DSS and dengue was confirmed only after autopsy completion. In the literature, such cases are usually described as atypical manifestations, published as separate reports, or described as exotic findings after autopsies (27) (28) (29) (30) (31) (32) (33) (34) (35) (36) (37).

We found that patients aged $>65$ years had a high possibility of death, which may be related in part to the high frequency of comorbidities reported in the elderly ${ }^{(38)(39)(40)(41)(42)(43)(44)}$.
Information on comorbidities is not included in the Brazilian Information System for Notifiable Diseases, and this information is obtained only through investigation of fatal dengue cases ${ }^{(4)(42)}$.

An important issue with the WHO 1997 classification is that countries usually adopt different methods to calculate fatality from dengue, and comparison of dengue case-fatality rates among different countries is difficult because countries interpret the DHF definition differently ${ }^{(45)}\left({ }^{46)}\right.$. We believe that the WHO 2009 classification facilitates comparisons of results and data from different countries.

In Brazil, fatality from dengue is calculated by dividing the number of DHF deaths by the number of confirmed cases of DHF. However, this indicator is influenced by the surveillance capacity to capture all suspected cases of DHF. Additionally, some regions divide the number of DHF deaths by population size. The WHO 2009 classification proposes that countries calculate the fatality from SD by dividing the number of deaths from SD by the population of each region, and then multiplying the obtained value by 1,000 . The adoption of the WHO 2009 classification should improve the comparison of dengue fatality rates among different countries because it captures severe cases ${ }^{(8)(15)(22)}$. It is believed that if this indicator is used, the fatality rates from dengue can be easily compared among different regions, considering population size and the impact of the disease in each region.

One important limitation of this study is that it included a small number of cases. The study could not obtain data from many patients because some were not hospitalized and epidemiological investigations were performed after postmortem examinations.

The WHO 2009 classification is more sensitive than the WHO 1997 classification for identifying dengue deaths among autopsied individuals suspected of having dengue.

\section{ACKNOWLEDGMENTS}

We thank the Evandro Chagas Institute, a reference center of the Ministry of Health of Brazil, for performing the immunohistochemical examinations. We thank Kiliana Escóssia from the Epidemiological Surveillance Center of Ceará Health Department for cooperating in the investigation of some deaths and Coroner's Office Dr. Rocha Furtado for providing data. We thank our colleagues Dr. Ronaldo Pinheiro and $\mathrm{Dr}^{\mathrm{a}}$ Susana Gloria (in memoriam) for research collaboration on some of the deaths.

\section{CONFLICT OF INTEREST}

The authors declare that there is no conflict of interest.

\section{FINANCIAL SUPPORT}

This study was supported by scholarships from Christus Academic Center (Centro Universitário Christus) (UNICHRISTUS) and the Ceará Foundation for Research Support (FUNCAP); process no. FUNCAP 12535699-4, edital no. 03/2012 - PPSUS - REDE-MS/CNPq/FUNCAP/SESA. 


\section{REFERENCES}

1. Simmons CP, Farrar JJ, Nguyen VV, Wills B. Dengue. New Engl J Med 2012; 366:1423-1432.

2. Bhatt S, Gething PW, Brady OJ, Messina JP, Farlow AW, Moyes $\mathrm{CL}$, et al. The global distribution and burden of dengue. Nature 2013; 496:504-507.

3. Teixeira MG, Costa MC, Coelho GE, Barreto ML. Recent shift in age pattern of dengue hemorrhagic fever, Brazil. Emerg Infect Dis 2009; 14:1663.

4. Cavalcanti LP, Coelho IC, Vilar DC, Holanda SG, Escóssia KN, Souza-Santos R. Clinical and epidemiological characterization of dengue hemorrhagic fever cases in northeastern Brazil. Rev Soc Bras Med Trop 2010; 43:355-358.

5. Cavalcanti LP, Vilar D, Souza-Santos R, Teixeira MG. Change in age pattern of persons with dengue, Northeastern Brazil. Emerg Infect Dis 2011; 17:132-134.

6. Ministério da Saúde (MS), Secretaria de Vigilância em Saúde. Dengue: diagnóstico e manejo clínico: criança. Brasília: SVS/MS; 2011.

7. Siqueira JB, Martelli CMT, Coelho GE, Simplício ACR, Hatch DL. Dengue and dengue hemorrhagic fever, Brazil, 1981-2002. Emerg Infect Dis 2005; 11:48-53.

8. Cavalcanti LP, Mota LA, Lustosa GP, Fortes MC, Mota DA, Lima AA, et al. Evaluation of the WHO classification of dengue disease severity during an epidemic in 2011 in the State of Ceará, Brazil. Mem Inst Oswaldo Cruz 2014; 109: 93-98.

9. World Health Organization (WHO). Dengue, guidelines for diagnosis, treatment, prevention and control. Geneva, Switzerland: WHO; 2009.

10. Alexander N, Balmaseda A, Coelho IC, Dimaano E, Hien TT, Hung NT, et al. Multicentre prospective study on dengue classification in four south-east Asian and three Latin American countries. Trop Med Int Health 2011; 16:936-948.

11. Srikiatkhachorn A, Gibbons RV, Green S, Libraty DH, Thomas SJ, Endy TP, et al. Dengue hemorrhagic fever: the sensitivity and specificity of the World Health Organization definition for identification of severe cases of dengue in Thailand, 1994-2005. Clin Infect Dis 2010; 50:1135-1143.

12. Narvaez F, Gutierrez G, Perez MA, Elizondo D, Nunez A, Balmaseda $\mathrm{A}$, et al. Evaluation of the traditional and revised WHO classifications of dengue disease severity. PLoS Negl Trop Dis 2011; 5:e1397.

13. Horstick O, Farrar J, Lum L, Martinez E, San Martin JL, Ehrenberg $\mathrm{J}$, et al. Reviewing the development, evidence base, and application of the revised dengue case classification. Pathog Glob Health 2012; 106:94-101

14. Prasad D, Kumar C, Jain A, Kumar R. Accuracy and applicability of the revised WHO classification (2009) of dengue in children seen at a tertiary healthcare facility in northern India. Infection 2013; 41:775-782.

15. Lima FR, Croda MG, Muniz DA, Gomes IT, Soares KR, Cardoso MR, et al. Evaluation of the traditional and revised World Health Organization classifications of dengue cases in Brazil. Clinics 2013; 68:1299-1304.

16. Macedo GA, Gonin MLC, Pone SM, Cruz OG, Nobre FF, Brasil P. Sensitivity and specificity of the World Health Organization dengue classification schemes for severe dengue assessment in children in Rio de Janeiro. PLoS One 2014; 9:e96314.

17. de Andrade SMO, Herkert CMM, da Cunha RV, Rodrigues MD, da Silva BAK. A new approach to reducing mortality from dengue. Open J Clin Diag 2014; 4:12-16.
18. Campos KB, Amâncio FF, Araújo VEM, Carneiro M. Factors associated with death from dengue in the state of Minas Gerais, Brazil: historical cohort study. Trop Med Int Health 2015; 20: 211-218.

19. Cavalcanti LPG, Braga D, Alexandre L, Aguiar M, Castiglioni M, Silva-Junior JU, et al. Postmortem Diagnosis of Dengue as an Epidemiological Surveillance Tool. Am J Trop Med Hyg 2015; 23: $\mathrm{e} 0392$.

20. Araújo FMC, Brilhante RSN, Cavalcanti LPG, Rocha MFG, Cordeiro RA, Perdigão $\mathrm{ACB}$, et al. Detection of the dengue non-structural 1 antigen in cerebral spinal fluid samples using a commercially available enzyme-linked immunosorbent assay. J Virol Met 2011; 177:128-131.

21. World Health Organization (WHO). Dengue hemorrhagic fever: diagnosis, treatment, prevention and control. $2^{\text {nd }}$ ed. Geneva: WHO; 1997.

22. Gutiérrez G, Gresh L, Pérez MÁ, Elizondo D, Avilés W, Kuan G, et al. Evaluation of the diagnostic utility of the traditional and revised WHO dengue case definitions. PLoS Negl Trop Dis 2013; 7:e2385.

23. Saw AK, Komgrid C, Ne W, Zin WK, Kyaw M, Nuntaya P, et al. Pathologic highlights of dengue hemorrhagic fever in 13 autopsy cases from Myanmar. Hum Pathol 2014; 45:1221-1233.

24. Verhagen LM, de Groot R. Dengue in children. J Infect 2014; 69:77-86.

25. Leo YS, Thein TL, Fisher DA, Low JG, Oh HM, Narayanan RL, et al. Confirmed adult dengue deaths in Singapore: 5-year multicenter retrospective study. BMC Infect Dis 2011; 11:1-7.

26. Tomashek KM, Gregory CJ, Rivera Sánchez A, Bartek MA, Garcia Rivera EJ, Hunsperger E, et al. Dengue deaths in Puerto Rico: lessons learned from the 2007 epidemic. PLoS Negl Trop Dis 2012; 6: e1614.

27. Souza LJ, Martins ALO, Raravidini PCL, Nogueira RMR, G Neto $\mathrm{C}$, Bastos DA, et al. Hemorrhagic encephalopathy in dengue shock syndrome: a case report. Braz J Infect Dis 2005; 9:257-259.

28. Kamath SR, Ranjit S. Clinical features, complications and atypical manifestations of children with severe forms of dengue hemorrhagic fever in South India. Indian J Pediatr 2006; 73:889-895.

29. Gulati S, Maheshwari, A. Atypical manifestations of dengue. Trop Med Int Health 2007; 12:1087-1095.

30. Ling LM, Smith AW, Leo YS. Fulminant hepatitis in dengue haemorrhagic fever. J Clin Virol 2007; 38:265-268.

31. Araújo SA, Moreira DR, Veloso JMR, Silva JO, Barros VLSR, Nobre V. Case report: fatal staphylococcal infection following classic dengue fever. Am J Trop Med Hyg 2010; 83:679-682.

32. Araújo F, Nogueira R, Araújo MS, Perdigão N, Cavalcanti L, Brilhante R. Dengue in patients with central nervous system manifestations, Brazil. Emerg Infect Dis 2012a; 18:677-679.

33. Araújo FMC, Araújo MS, Nogueira RMR, Brilhante RSN, Oliveira $\mathrm{DN}$, Rocha MFG, et al. Central nervous system involvement in dengue: A study in fatal cases from a dengue endemic area. Neurology 2012b; 78:736-742.

34. Kalaratne SAM, Imbulpitiya IVB, Abeysekera RA, Waduge RN, Rajapakse RPVJ, Weerakoon KGAD. Extensive haemorrhagic necrosis of liver is an unpredictable fatal complication in dengue infection: a postmortem study. BMC Infect Dis 2014; 14:141-151.

35. Ribeiro BNF, Guimarães AC, Yazawa F, Takara TFM, Carvalho GM, Zappeline CEM. Sensorineural hearing loss in hemorrhagic dengue? Int J Sur Case Rep 2014; 8:38-41.

36. Rivera J, Neira M, Parra E, Méndez J, Sarmiento L, Caldas ML. Detección de antígenos del virus del dengue en tejidos post mórtem. Biomédica 2014; 34:514-520. 
37. Yacoub S, Wertheim H, Simmons CP, Screaton G, Wills B. Cardiovascular manifestations of the emerging dengue pandemic. Nat Rev Card 2014; 11:335-345.

38. Passos MC, Figueiredo MAA. Mortalidade por dengue no Estado da Bahia. Rev Baiana Saude Publica 2011; 35:687-694.

39. Figueiró AC, Hartz ZMA, Brito CAA, Samico I, Siqueira-filha NT, Cazarin G, et al. Death from dengue fever as a sentinel event for evaluation of quality of healthcare: a case study in two municipalities in Northeast Brazil, 2008. Cad Saude Publica 2011; 27:2373-2385.

40. Moraes GH, Duarte EC. Reliability of dengue mortality data in two national health information systems, Brazil, 2000-2005. Cad Saude Publica 2009; 25:2354-2364.

41. Ong A, Sandar M, Chen MI, Sin LY. Fatal dengue hemorrhagic fever in adults during a dengue epidemic in Singapore. Int J of Infect Dis 2007; 11:263-267.
42. Moraes GH, Duarte EF, Duarte EC. Determinants of mortality from severe dengue in Brazil: a populations-based case-control study. Am J Trop Med Hyg 2013; 88:670-676.

43. Lye DC, Lee VJ, Sun Y, Leo YS. The benign nature of acute dengue infection in hospitalized older adults in Singapore. Int $\mathrm{J}$ Infect Dis 2010; 14:e410-e413.

44. Thein TL, Leo YS, Fisher DA, Low JG, Oh HML, Gan VC, et al. Risk factors for fatality among confirmed adult dengue inpatients in Singapore: a matched case-control study. PLoS One 2013; 8:e81060.

45. Guha-Sapir D, Schimmer B. Dengue fever: new paradigms for a changing epidemiology. Emerg Them Epidem 2005; 2:1-10.

46. Teixeira MG, Siqueira Jr JB, Ferreira GLC, Bricks L, Joint G. Epidemiological trends of dengue disease in Brazil (2000-2010): a systematic literature search and analysis. PLoS Negl Trop Dis 2013; 7:e2520. 